\title{
Prognostic and predictive value of monocarboxylate transporter 4 in patients with breast cancer
}

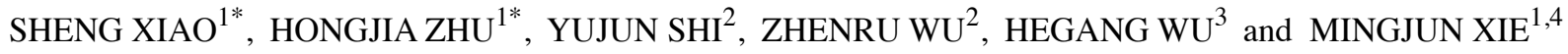 \\ ${ }^{1}$ School of Clinical Medicine, Southwest Medical University, Luzhou, Sichuan $646000 ;{ }^{2}$ Laboratory of Pathology, \\ Key Laboratory of Transplant Engineering and Immunology, NHFPC, West China Hospital, Chengdu, Sichuan 610000; \\ Departments of ${ }^{3}$ Pathology and ${ }^{4}$ Breast Surgery, The First People's Hospital of Yibin, Yibin, Sichuan 644000, P.R. China
}

Received November 16, 2019; Accepted April 23, 2020

DOI: $10.3892 / \mathrm{ol} .2020 .11776$

\begin{abstract}
The Warburg effect explains the large amount of lactic acid that tumour cells produce to establish and maintain the acidic characteristics of the tumour microenvironment, which contributes to the migration, invasion and angiogenesis of tumour cells. Monocarboxylate transporter 4 (MCT-4) is a key marker of tumour glycolysis and lactic acid production; however, the role of MCT-4 in breast cancer remains unclear. In the present study, immunohistochemistry (IHC) was used to detect the expression levels of MCT-4 in tissue microarrays of 145 patients diagnosed with invasive ductal breast cancer. The IHC score was used to assess the intensity of staining and the proportion of positive cells. Western blotting and reverse transcription-quantitative PCR were also performed to detect the expression levels of MCT-4 in 30 pairs of breast cancer tissues and adjacent normal tissues. In vitro experiments (EdU incoporation and Cell Counting Kit-8) were performed to examine the role of MCT-4 in the breast cancer MCF-7 cell line. The results of the present study indicated that high MCT-4 expression was associated with pT status $(\mathrm{P}=0.018)$, oestrogen receptor $(\mathrm{ER})$ status $(\mathrm{P}=0.001)$, progesterone receptor $(\mathrm{PR})$ status $(\mathrm{P}=0.024), \mathrm{Ki} 67$ index $(\mathrm{P}=0.043)$ and androgen receptor $(\mathrm{AR})$ status $(\mathrm{P}=0.033)$. In addition, an association between MCT-4 expression and pathological grade was observed $(\mathrm{P}=0.030)$. Furthermore, univariate $(\mathrm{P}=0.027)$ and multivariate $(\mathrm{P}=0.001)$ survival analysis revealed that MCT-4 expression and lymph node involvement were significant independent predictors of breast cancer prognosis. In addition, silencing MCT-4 expression attenuated breast cancer
\end{abstract}

Correspondence to: Professor Mingjun Xie, School of Clinical Medicine, Southwest Medical University, 1 Xianglin Road, Luzhou, Sichuan 646000, P.R. China

E-mail: xiemingjun886@126.com

${ }^{*}$ Contributed equally

Key words: breast neoplasms, monocarboxylate transporter 4, prognosis, Warburg effect, cell viability cell viability. Therefore, MCT-4 may be used as a potential predictor of invasive breast cancer.

\section{Introduction}

Breast cancer is one of the most common malignancies affecting the life of women worldwide. Although the widespread use of adjuvant chemotherapy and hormonal drugs has reduced breast cancer mortality, breast cancer remains the leading cause of mortality among women $<50$ years of age (1). Breast cancer is a complex polygenic disease and an abnormal metabolic disease. It is well known that the viability of tumour cells is associated with their specific metabolism. Cancer cells are usually hyperproliferative and exhibit a higher rate of glycolysis compared with normal cells. Glycolysis is part of the energy metabolism of cancer cells and is an important way to generate ATP. Cancer cells reprogram their metabolism to shift from using pyruvate for oxidative phosphorylation to using lactate, which means tumour cells use a large amount of glucose for glycolysis and produce a large amount of lactate; this shift is known as the Warburg effect (2). The high rate of glycolysis in tumour cells maintains the acidic characteristics of the tumour microenvironment, which is associated with tumour invasion features, such as growth advantages and increased survival, migration, invasion and angiogenes $(3,4)$.

Monocarboxylate transporters (MCTs) mediate the transport of various monocarboxylates, including lactate, pyruvate and ketone, across cell membranes (5). Tumour cells rely on MCTs to transport large amounts of lactate out of the cell, thereby avoiding intracellular acidification and cell death. The MCT family consists of 14 members. Among these, MCT1-4 are preferentially involved in the transport of lactic acid (6). MCT-1 is relatively ubiquitously expressed in a number of tissues and serves a role in lactate shuttles in the heart, slow-twitch muscles, red blood cells and liver (7). Other MCT proteins exhibit stronger tissue-specific expression, such as MCT-2 being present in neurons, and MCT-3 being restricted to retinal pigment and choroid plexus epithelium (8). MCT-4 is limited to the glycolysis pathway. MCT-4 is located in the cell membrane and transports lactic acid through a $\mathrm{pH}$ gradient. MCT-4 has been demonstrated to be overexpressed in multiple types of cancer, including melanoma, and cervical, colorectal, kidney and lung cancer (9-19). It has been demonstrated that 
MCT-4, as a marker of glycolysis and lactic acid production, can prevent $\mathrm{pH}$ lowering and inhibit sustained glycolysis by exporting lactic acid in tumour cells (20).

However, the clinical relevance of MCT-4 expression in breast cancer has not been fully elucidated. Therefore, the present study aimed to investigate the predictive effect of MCT-4 expression on overall survival (OS) in patients with breast cancer, and to evaluate its clinicopathological significance, thus potentially identifying a novel potential therapeutic target for the treatment of breast cancer.

\section{Materials and methods}

Patients and tissues. A total of 145 samples were collected from 145 female patients with confirmed breast cancer at The First People's Hospital of Yibin (Yibin, China) affiliated with Southwest Medical University. The average age of the patients was 60 years (range, 33-88 years). The follow-up began on the day of surgery and ended in July 2014, ranging between 2 and 119 months. All patients underwent surgery between August 2004 and December 2008, including modified radical mastectomy or lumpectomy with axillary lymphonodectomy. According to the World Health Organization Classification of Tumors of the Breast (21), the basic clinicopathological data are shown in Table I. The haematoxylin and eosin-stained tissue specimens were reviewed from 145 paraffin samples. Cylindrical core tissue samples (0.6- $\mathrm{mm}$ diameter) were taken from the most representative area of each paraffin block and aligned into a new acceptor paraffin block (20x35 mm) using precision instruments. If the histopathological diagnosis lacked a clear date or the sample did not contain enough cancer cells at the tissue chip point, the sample was excluded from the present study. OS time was defined as the date from initial diagnosis to the last follow-up or death. The exclusion criteria were as follows: i) Patients lost to follow-up; ii) died of other diseases, iii) died of accidents, iv) lacked a clear date of death and v) the sample did not contain enough cancer cells at the tissue chip point. The clinicopathological parameters of patients in the present study and the relevant dates of long-term follow-up were obtained from hospitals. In addition, 30 fresh breast cancer tissues and paired adjacent normal tissues $(5 \mathrm{~cm}$ away from primary tumour site) were collected from The First People's Hospital of Yibin affiliated with Southwest Medical University and stored at $-80^{\circ} \mathrm{C}$ prior to protein extraction. The mean age of the patients was 52 years (range, 35-67 years). The date of surgery was between January 5, 2018 and December 22,2018 . The present study was conducted in accordance with the Declaration of Helsinki and the Guiding Principles of The First People's Hospital of Yibin Ethics Review Committee and Southwest Medical University.

Cell culture and transfection. The MCF-7 cell line, obtained from the American Type Culture Collection, was maintained in Minimum Essential Medium supplemented (MEM; cat. no. SH30024) with 10\% FBS (cat. no. SH30396; both from Hyclone; Cytiva), $2 \mathrm{mM} / 1$ glutamine and $100 \mathrm{U} / \mathrm{ml}$ penicillin/streptomycin. Cells were maintained at $37^{\circ} \mathrm{C}$ in a $5 \%(\mathrm{v} / \mathrm{v}) \mathrm{CO}_{2}$ atmosphere and sub-cultured every 3 days. Transfection with small interfering (si)RNAs (50 nM; Guangzhou RiboBio Co., Ltd.) against the MCT-4 gene
(siMCT-4; 5'-TCCCATGGCCAGGAGGGTTG-3') was performed using Lipofectamine ${ }^{\circledR} 3000$ (Thermo Fisher Scientific, Inc.). Scrambled siRNA (5'-CCAUGAGGAGUA CUGCCAATT-3') was used as a negative control. A total of $2 \times 10^{5}$ cells/well were seeded in a 6 -well plate in complete medium ( $2 \mathrm{ml} /$ well). According to the manufacturer's protocol, when the cells reached $80 \%$ confluence, Solution A (P3000 ${ }^{\mathrm{TM}}$ Reagent with siRNAs) and Solution B (Lipofectamine ${ }^{\mathrm{TM}} 3000$ reagent; both from the Lipofectamine ${ }^{\circledR} 3000$ kit; Thermo Fisher Scientific, Inc.) were diluted in serum-free medium, respectively, mixed with each other and incubated at room temperature for 10-15 min. Cells were washed with $2 \mathrm{ml}$ serum-free medium, the complex solution was added to each well and cells were cultured at $37^{\circ} \mathrm{C}$ in a $5 \% \mathrm{CO}_{2}$ humidified incubator for $24 \mathrm{~h}$. Subsequently, the culture medium with transfection regents was replaced with fresh complete medium to remove the influence of transfection regents on cell biological behaviours. After $72 \mathrm{~h}$ incubation at $37^{\circ} \mathrm{C}$, western blotting was performed to detect whether MCT-4 expression was successfully silenced.

Cell Counting Kit-8 (CCK-8) and 5-ethynyl-2'-deoxyuridine (EdU) incorporation assay. To assess cell viability, a CCK-8 assay (Sigma-Aldrich; Merck KGaA) was performed according to the manufacturer's protocol. Subsequently, EdU integration (Guangzhou RiboBio Co., Ltd.) was performed. After transfection, cells were seeded into 96-well plates with $\sim 5 \times 10^{3}$ cells/well and incubated at $37^{\circ} \mathrm{C}$ until cells reached $30 \%$ confluence. According to the manufacturer's protocol, the EdU assay was performed using a Cell-Light EdU Apollo 567 in vitro kit (cat. no. 100T; Changzhou Ruibo Biotechnology Co., Ltd.).

Immunohistochemical staining. Samples were fixed in $4 \%$ paraformaldehyde (cat. no. P6148; Merck KGaA) for $48 \mathrm{~h}$ at room temperature. Immunohistochemical staining was used to assess the expression levels of MCT-4. Tissue microarrays (TMAs, $4 \mu \mathrm{m}$ ) were dewaxed twice in xylene for $15 \mathrm{~min}$ each at room temperature and rehydrated three times in a descending alcohol series $(100,100,95$ and 80\%). Antigen retrieval was performed with citric acid buffer (10 mM; pH 6.0) in a microwave $(800 \mathrm{~W})$ for $15 \mathrm{~min}$, and samples were cooled at room temperature for $30 \mathrm{~min}$. Subsequently, sections were blocked with $0.5 \%$ goat serum (cat. no. SL038; Beijing Solarbio Science \& Technology Co., Ltd.) and incubated with $3 \% \mathrm{H}_{2} \mathrm{O}_{2}$ (cat. no. 323381; Merck KGaA) to inhibit endogenous peroxidase activity, both at room temperature for $30 \mathrm{~min}$. The samples were incubated with anti-MCT-4 primary antibody (dilution, 1:100 in TBS; cat. no. sc-376140; Santa Cruz Biotechnology, Inc.) at $4^{\circ} \mathrm{C}$ overnight. The TMAs were subsequently washed with PBS for $5 \mathrm{~min}$ and incubated with a goat anti-mouse secondary antibody (dilution, 1:2,000 for immunohistochemistry; cat. no. HA1001; Hangzhou HuaAn Biotechnology Co., $\mathrm{Ltd}$ ) for $1 \mathrm{~h}$ at $37^{\circ} \mathrm{C}$. The colour was developed with 3-3'-diaminobenzidine. Subsequently, sections were counterstained with hematoxylin solution (cat. no. 51275; Merck KGaA) for $5 \mathrm{~min}$, rinsed with tap water repeatedly until the water became clear, and subsequently differentiated using 1-2\% hydrochloric acid (cat. no. H1758; Merck KGaA) for 1-2 sec, all of which were performed at room temperature. The nuclei and cytoplasm of 
Table I. Patient clinicopathological characteristics $(n=145)$.

\begin{tabular}{|c|c|c|}
\hline Characteristics & Samples, $\mathrm{n}$ & $\%$ \\
\hline \multicolumn{3}{|l|}{ Age, years } \\
\hline$\leq 60$ & 83 & 57.2 \\
\hline$>60$ & 62 & 42.8 \\
\hline \multicolumn{3}{|l|}{ pT stage } \\
\hline pT1 & 36 & 24.8 \\
\hline pT2 & 90 & 62.1 \\
\hline pT3 & 17 & 11.7 \\
\hline pT4 & 2 & 1.4 \\
\hline \multicolumn{3}{|l|}{$\mathrm{N}$ stage } \\
\hline N0 & 74 & 51.0 \\
\hline N1 & 38 & 26.2 \\
\hline N2 & 18 & 12.4 \\
\hline N3 & 15 & 10.4 \\
\hline \multicolumn{3}{|l|}{ M stage } \\
\hline M0 & 145 & 100 \\
\hline M1 & 0 & 0 \\
\hline \multicolumn{3}{|l|}{ Histologic grade } \\
\hline G1 & 4 & 2.8 \\
\hline $\mathrm{G} 2$ & 121 & 83.4 \\
\hline G3 & 20 & 13.8 \\
\hline \multicolumn{3}{|l|}{ TNM stage } \\
\hline I & 23 & 15.9 \\
\hline II & 83 & 57.2 \\
\hline III & 39 & 26.9 \\
\hline \multicolumn{3}{|c|}{ Oestrogen receptor } \\
\hline Negative & 57 & 41.6 \\
\hline Positive & 80 & 58.4 \\
\hline \multicolumn{3}{|c|}{ Progesterone receptor } \\
\hline Negative & 88 & 64.2 \\
\hline Positive & 49 & 35.8 \\
\hline \multicolumn{3}{|c|}{$\begin{array}{l}\text { Human epidermal growth } \\
\text { factor receptor }\end{array}$} \\
\hline Negative & 97 & 70.3 \\
\hline Positive & 41 & 29.7 \\
\hline \multicolumn{3}{|l|}{$\mathrm{Ki} 67, \%$} \\
\hline Low $(<14)$ & 85 & 62.5 \\
\hline High $(\geq 14)$ & 51 & 37.5 \\
\hline \multicolumn{3}{|c|}{ Androgen receptor } \\
\hline Negative & 43 & 30.9 \\
\hline Positive & 96 & 69.1 \\
\hline
\end{tabular}

TNM, tumor-node-metastasis.

breast cancer cells were observed using a light microscope (magnification, x200).

Western blotting. Fresh tissue samples ( 100 mg) were collected from 30 patients with breast cancer and cut into pieces with surgical scissors in lysis buffer (1\% Triton X-100, $150 \mathrm{mM}$
$\mathrm{NaCl}, 10$ mM Tris pH 7.4, 1 mM EDTA, 1 mM EGTA pH 8.0, $0.2 \mathrm{mM}$ sodium orthovanadate and protease inhibitors), and the protein concentration was quantified using a bicinchoninic acid protein assay kit. Protein lysate (50 $\mu \mathrm{g} /$ lane) were separated via SDS-PAGE on a $10 \%$ gel and transferred to a PVDF membrane, which were blocked with $5 \%$ skimmed milk for $1 \mathrm{~h}$ at room temperature. Membranes were incubated with anti-MCT-4 primary antibody (dilution, 1:1,000 in BSA; cat. no. sc-376140; Santa Cruz Biotechnology, Inc.) and non-conjugated internal reference antibodies, anti-GAPDH (dilution, 1:5,000; cat. no. EM1101) and anti- $\beta$-actin (dilution, 1:5,000; cat. no. EM21002) at $4^{\circ} \mathrm{C}$ overnight (both from Hangzhou HuaAn Biotechnology Co., Ltd.). The membrane was washed with TBS-Tween $(0.1 \%)$ and incubated with goat anti-mouse secondary antibody for $60 \mathrm{~min}$ at $37^{\circ} \mathrm{C}$. Pierce enhanced chemiluminescent reagent (cat. no. NCI4106; Pierce; Thermo Fisher Scientific, Inc.) was added, and the membrane was exposed to X-ray film in the dark. Protein bands were semi-quantitatively analysed using Quantity One software (version 4.6.6, Bio-Rad Laboratories, Inc.).

Reverse transcription-quantitative PCR (RT-qPCR). Total RNA was extracted from breast cancer tissues and paired adjacent tissues using TRIzol reagent (Takara Bio, Inc.). The PrimeScript RT kit (Takara Bio, Inc.) was used for reverse transcription to cDNA with the following temperature protocol: $35^{\circ} \mathrm{C}$ for $5 \mathrm{~min}, 42^{\circ} \mathrm{C}$ for $40 \mathrm{~min}$ and $75^{\circ} \mathrm{C}$ for $5 \mathrm{~min}$. Subsequently, qPCR was performed using SYBR Premix Ex Taq II (Takara Bio, Inc.) and the LightCycler system (Roche Diagnostics $\mathrm{GmbH}$ ). The results were analysed using the $2^{-\Delta \Delta \mathrm{Cq}}$ method (22). GAPDH was used as an internal control. The primer sequences were as follows: MCT-4 forward, 5'-CCA TGCTCTACGGGACAGG-3' and reverse, 5'-GCTTGCTGA AGTAGCGGTT-3'; and GAPDH forward, 5'-GGAGCGACA TCCGTCCAAAAT-3' and reverse, 5'-GGCTGTTGTCAA TCTTCTCATGG-3'. The thermocycling conditions for qPCR were as follows: Initial activation step at $95^{\circ} \mathrm{C}$ for $15 \mathrm{~min}$, followed by 40 cycles of denaturation at $94^{\circ} \mathrm{C}$ for $15 \mathrm{sec}$, annealing at $55^{\circ} \mathrm{C}$ for $30 \mathrm{sec}$, extension at $72^{\circ} \mathrm{C}$ for $30 \mathrm{sec}$ and a final extension at $72^{\circ} \mathrm{C}$ for $5 \mathrm{~min}$, and the amplification product was kept at $4^{\circ} \mathrm{C}$.

Scoring of the staining results. MCT-4 expression was observed and analysed based on the intensity of staining (IS; 0 , negative; 1 , weak; 2 , moderate; 3 , strong) and the area of positive staining (AP; $0,<5 \% ; 1,5-25 \% ; 2,26-50 \% ; 3,51-75 \%$; $4,>75 \%$ ). The final immunoreactivity score of MCT-4 expression was determined using the following formula: Intensity distribution (ID)=AP $x$ IS. To determine the cut-off value of the expression level (high or low) of MCT-4, receiver operating characteristic (ROC) curve analysis of the OS rate was performed. The TMA was independently analysed by two experienced pathologists who were blinded to the clinical characteristics of patients.

Statistical analysis. Statistical analysis was performed using SPSS software 19.0 (IBM Corp.) and GraphPad Prism software 6.0 (GraphPad Software, Inc.). Data are presented as the mean \pm standard deviation. The paired t-test was used for comparisons between two groups. ROC curve analysis 
was performed to determine the cut-off point for high or low MCT-4 expression. The association between MCT-4 immunofluorescence staining and clinicopathological parameters of patients with breast cancer was analysed by $\chi^{2}$ test and Fisher analysis. The Kaplan-Meier method was used to assess the importance of prognosis and the log-rank test was used to assess the survival curves. Univariate and multivariate analyses of survival data were performed using the Cox proportional hazard model approach to analyse independent prognostic values. $\mathrm{P}<0.05$ was considered to indicate a statistically significant difference.

\section{Results}

Patient characteristics. At the end of the follow-up period, 102 patients (70.3\%) survived, while 43 (29.7\%) died of breast cancer. The follow-up period ranged between 2 and 119 months (mean, 76 months; Table SI). With regard to the tumour diameter (pT), 36 samples (24.8\%) were pT1, 90 samples $(62.1 \%)$ were pT2, 17 samples $(11.7 \%)$ were pT3 and 2 samples (1.4\%) were pT4. With regard to the degree of lymph node involvement $(\mathrm{N}), 74(51.0 \%)$ patients were N0, $38(26.2 \%)$ were $\mathrm{N} 1$, $18(12.4 \%)$ were $\mathrm{N} 2$ and $15(10.4 \%)$ were N3. There was no distant metastasis (M) observed. Considering these three aspects, 23 samples (15.9\%) were classified as TNM stage I, 83 samples (57.2\%) were stage II and 39 samples (26.9\%) were stage III. In terms of histologic grade, 4 patients $(2.8 \%)$ were G1, 121 (83.4\%) were G2 and 20 (13.8\%) were G3. Other clinicopathological factors are listed in Table I.

Cut-off value of MCT-4 expression. To accurately obtain cut-off values for high and low expression levels, ROC curve analysis was performed for OS (Fig. 1). Based on the optimal sensitivity and specificity, an ID score of 1.5 was determined as the cut-off score for MCT- 4 expression in breast cancer (ID score $\geq 1.5$ indicated high expression and $<1.5$ indicated low expression).

MCT-4 expression in normal breast and breast cancer tissues. A positive MCT-4 signal was mainly observed on the cell membrane, as well as in the cytoplasm of tumour cells (Fig. 2). A total of 63 (43.4\%) samples exhibited high MCT-4 expression, while 82 (56.6\%) exhibited low MCT-4 expression. No high MCT- 4 expression was detected in the 30 corresponding normal breast cancer tissues. Additionally, RT-qPCR and western blotting demonstrated that MCT- 4 expression in breast cancer tissues was significantly higher than in adjacent normal tissues (Fig. 3).

Clinical significance and prognostic value of MCT-4 expression. To analyse the effect of MCT- 4 expression on tumour aggressiveness, the association between MCT- 4 expression and clinicopathological features was assessed using the $\chi^{2}$ test (Table II). A significant association was detected between high MCT-4 expression and $\mathrm{pT}$ stage $(\mathrm{P}=0.018)$. High MCT-4 expression was associated with oestrogen receptor (ER) status $(\mathrm{P}=0.001)$, progesterone receptor $(\mathrm{PR})$ status $(\mathrm{P}=0.004), \mathrm{Ki67}$ index $(\mathrm{P}=0.043)$ and androgen receptor $(\mathrm{AR})$ status $(\mathrm{P}=0.033)$. In addition, a close association was observed between MCT-4 expression and histological grade $(\mathrm{P}=0.030)$. No significant

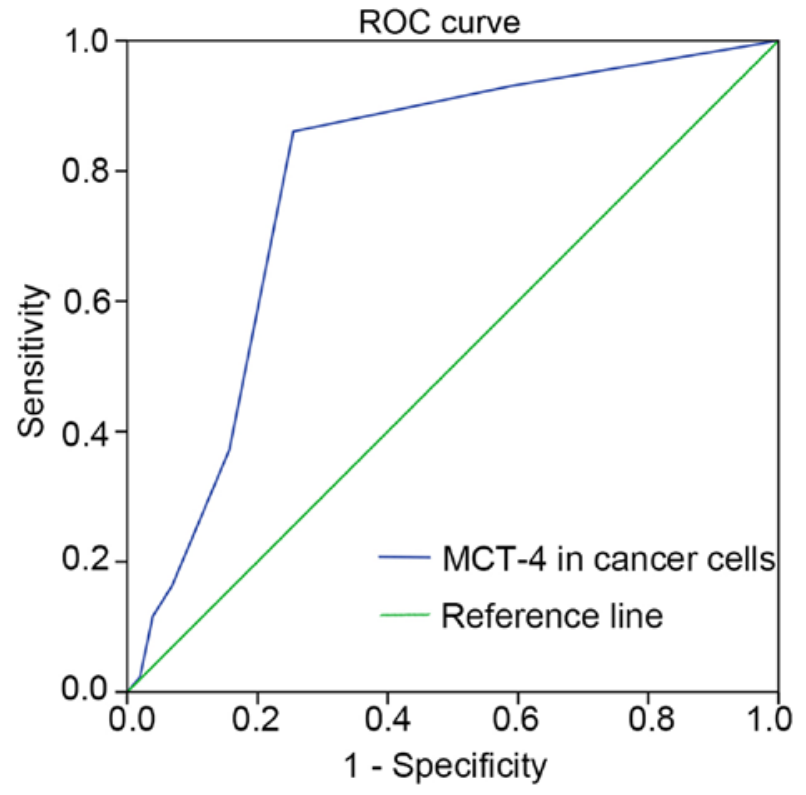

Figure 1. ROC analysis of MCT-4 scores of patients with breast cancer for overall survival rate. A cut-off value for MCT-4 expression associated with the optimal sensitivity and specificity was defined. Area under the curve, $0.786 ; 95 \% \mathrm{CI}, 0.706-0.865 ; \mathrm{P}=0.001$. ROC, receiver operating characteristic; MCT-4, monocarboxylate transporter 4.

association was identified between MCT-4 expression and any other clinicopathological variable (Table II).

In addition, the Kaplan-Meier method with a log-rank test was used to estimate survival curves for OS rates and to assess differences in survival between patients with high and low MCT-4 expression. The mean OS time for the high MCT-4 expression group was 62.1 months, whereas that for the low MCT-4 expression group was 87.9 months. Survival curves indicated that high MCT-4 expression in breast cancer predicted a significantly reduced likelihood of survival $(\mathrm{P}<0.001$; Fig. 4). In addition, the Cox proportional hazards regression model was used to identify independent prognostic factors in patients with breast cancer. Multivariate analysis revealed that MCT-4 expression and lymph node involvement were significantly associated with OS in patients with breast cancer $(\mathrm{P}=0.027)$. However, other clinicopathological features failed to independently predict breast cancer prognosis (Table III). The results of the present study indicated that low MCT-4 expression was significantly associated with a reduced risk of mortality compared with high MCT- 4 expression in patients with breast cancer. Multivariate analysis was performed as shown in Table III. Similar to univariate analysis, MCT-4 expression and lymph node involvement were significant independent predictors of breast cancer prognosis.

MCT-4 promotes cell viability in vitro. To investigate the biological effects of MCT-4 on breast cancer cell viability, MCT-4 expression was silenced in the MCF-7 cell line (Fig. 5A), and the CCK-8 analysis revealed that MCT-4 knockdown significantly decreased MCF-7 cell viability (Fig. 5B). Additionally, reduced MCT-4 expression significantly inhibited MCF-7 cell viability as assayed by EdU incorporation (Fig. 5C). 

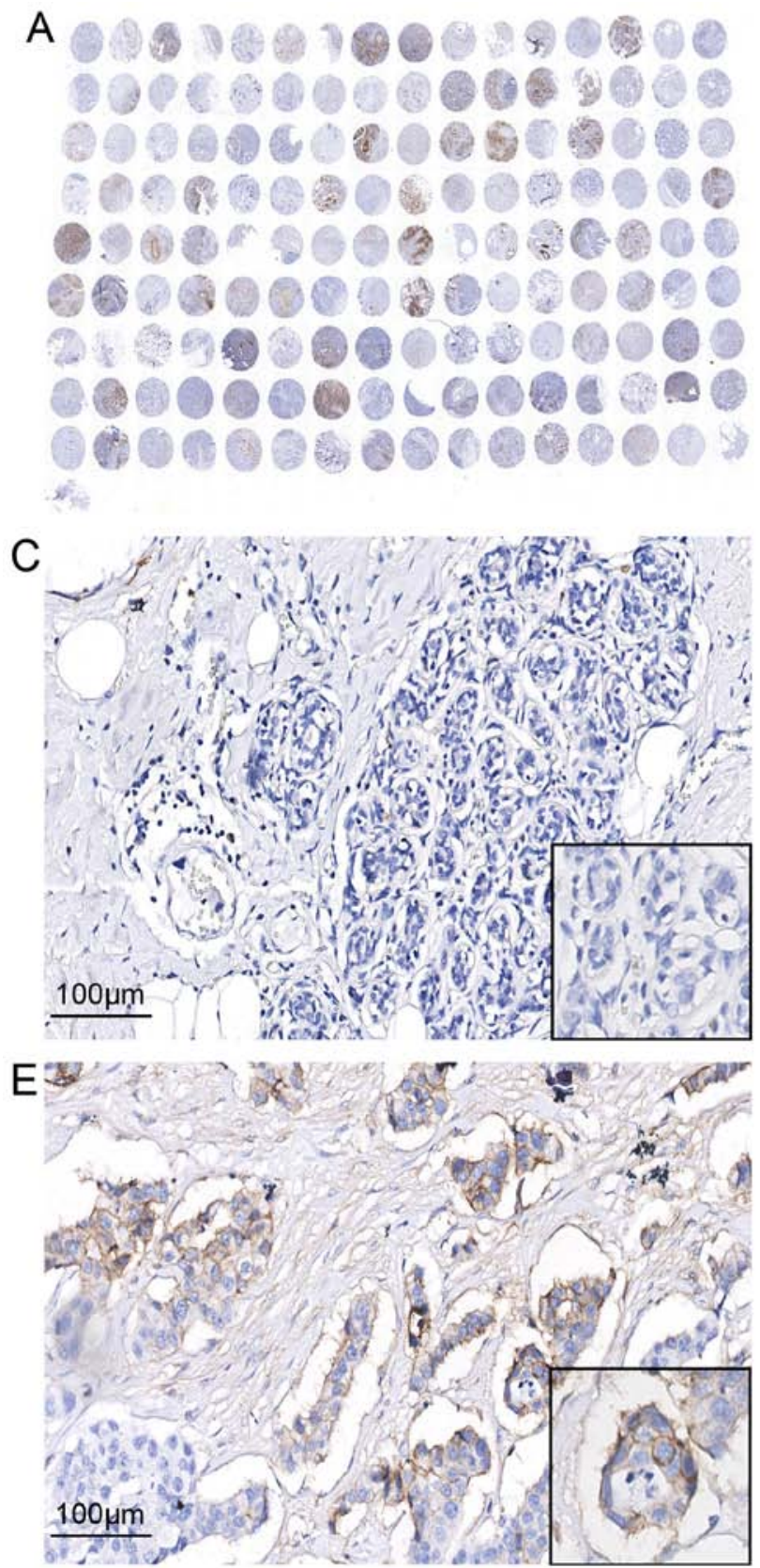
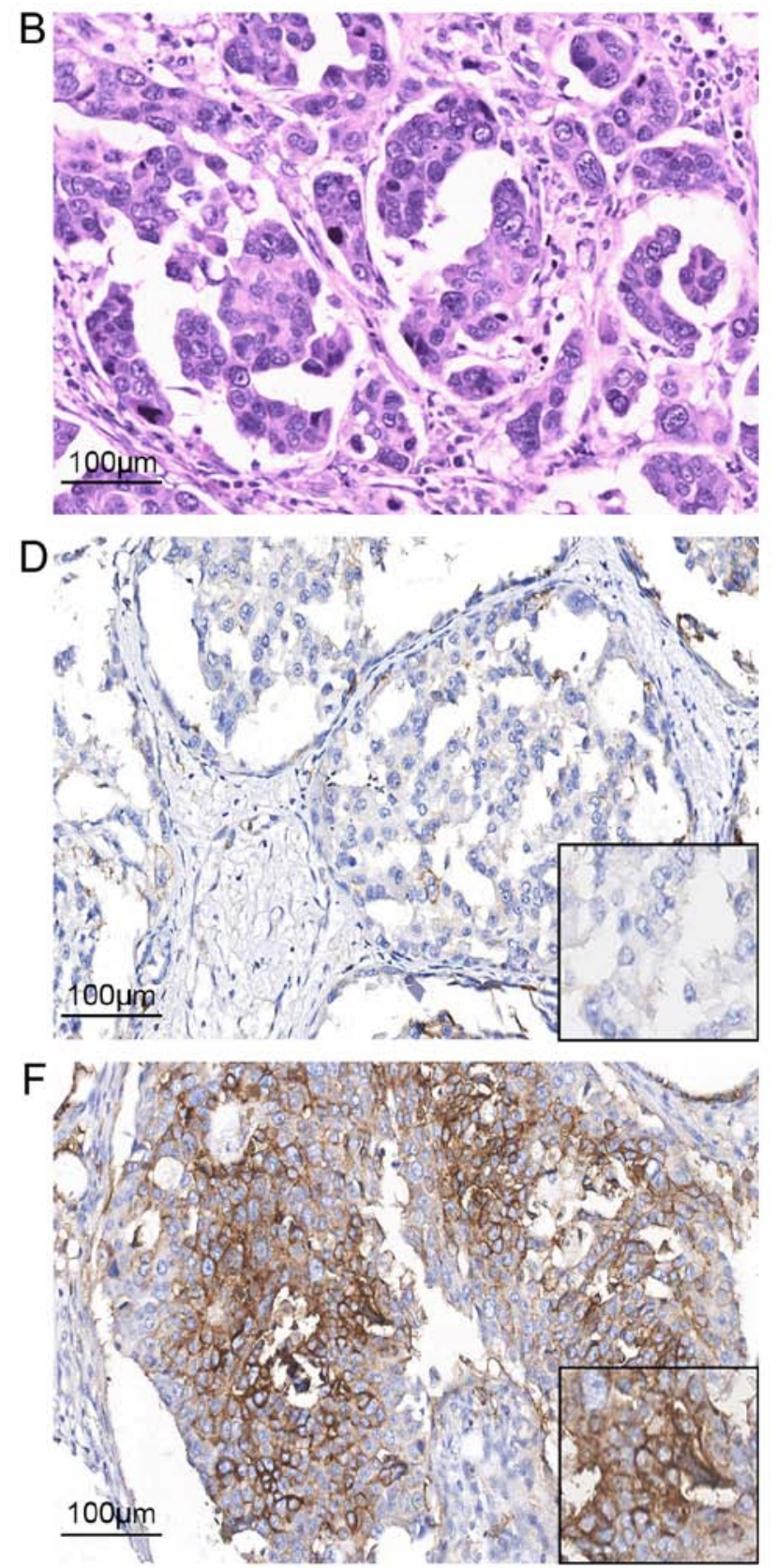

Figure 2. MCT-4 expression results. (A) Tissue microarray. (B) Hematoxylin and eosin-stained tissue specimens. (C) Negative expression of MCT-4. (D) Representation of low MCT-4 expression. (E) Representation of moderate MCT-4 expression. (F) Representation of strong MCT-4 expression. MCT-4, monocarboxylate transporter 4.

\section{Discussion}

The role of the MCT family in abnormal tumour metabolism has received increasing attention from researchers in recent years. The present study revealed that staining of MCT-4 appeared mainly in the cell membrane and cytoplasm of tumour cells, and that it was expressed at low levels in the stromal cells of breast cancer tissues. Additionally, the association between MCT-4 expression and clinical parameters associated with prognosis was explored. High MCT-4 expression was associated with advanced stage (pT3+pT4) and histological grade of breast cancer. MCT-4 knockdown significantly reduced MCF-7 cell viability in vitro. Therefore, high MCT-4 expression may predict poor prognosis in breast cancer, and MCT-4 may be a candidate therapeutic target in patients with breast cancer. However, the present study contains a limitation, in that only one cell line was used to explore MCT-4 expression in breast cancer cells. Multiple breast cancer cell lines should be included in future experiments.

The findings of the present study are consistent with previous studies by Pinheiro et al (5) demonstrating an increase in MCT-4 expression in breast cancer and by Maria et al (23) reporting that MCT-4 is highly expressed in a patient with breast cancer with a high histological grade. However, both of these studies lacked detailed information on the association between MCT-4 expression and clinical features of breast cancer, including ER, PR, Ki67, AR and human epidermal growth factor receptor 2 (HER2) expression. In addition, they 

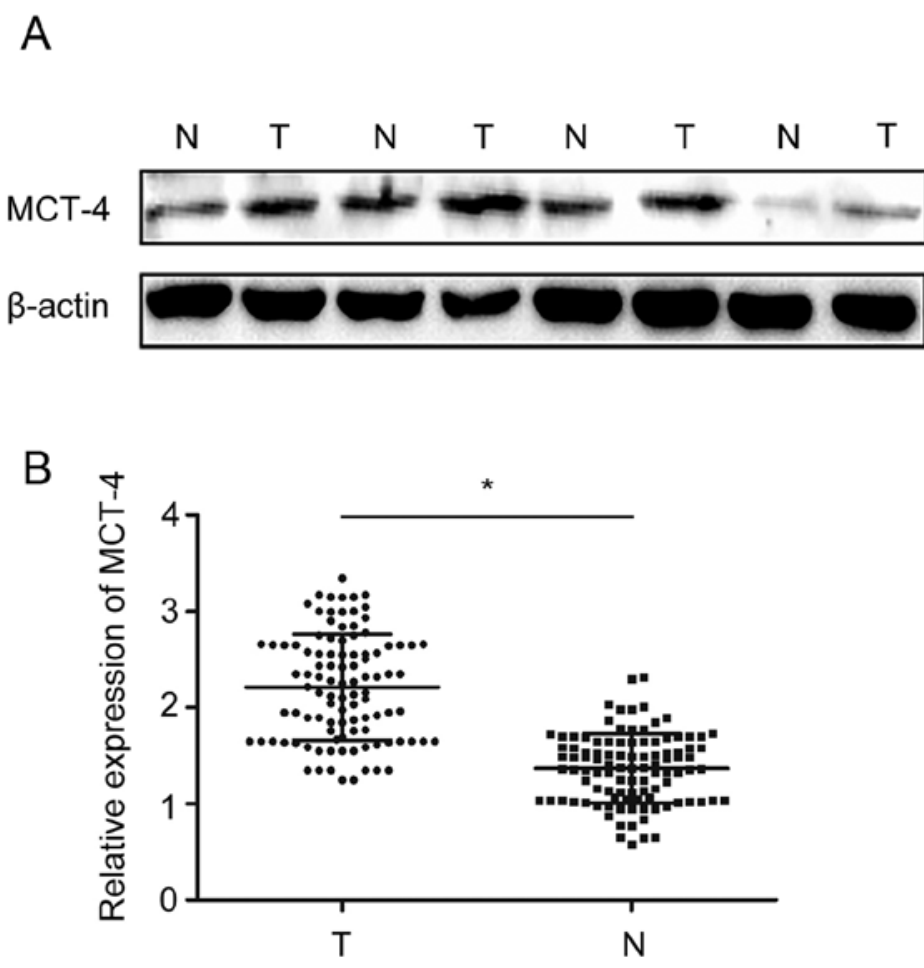

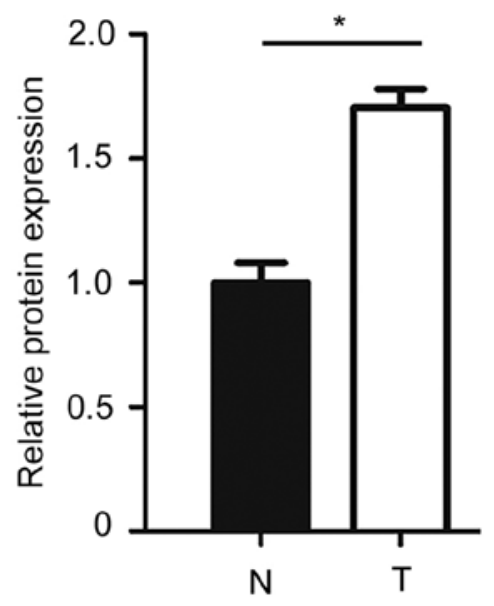

Figure 3. MCT-4 expression in breast cancer. (A) Western blotting and semi-quantification of MCT-4 expression in breast cancer and corresponding normal tissues. (B) Relative MCT-4 expression in breast cancer and paired adjacent tissues. ${ }^{*} \mathrm{P}<0.05$. T, tumor; N, non-tumor; MCT-4, monocarboxylate transporter 4.

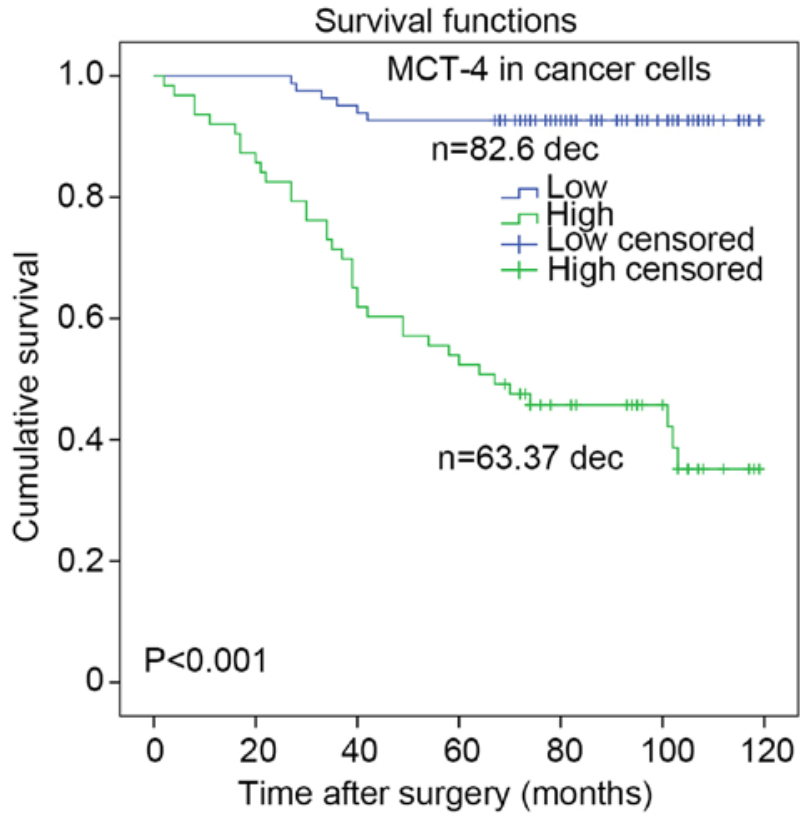

Figure 4. Cumulative survival curves of patients with breast cancer. High MCT-4 expression was associated with a reduced overall survival rate in patients with breast cancer compared with low MCT-4 expression $(\mathrm{P}<0.001$; high vs. low expression; log-rank test). MCT-4, monocarboxylate transporter 4; dec., deceased.

did not report the association between MCT-4 expression and pathological features or long-term survival rate. In the present study, silencing the MCT-4 gene significantly attenuated breast cancer cell viability. The high expression levels of MCT-4 in the cytoplasm may indicate that it is involved in other cellular functions (24).

Interestingly, in the present study, high MCT-4 expression was closely associated with triple-negative breast cancer (TNBC; $\mathrm{P}=0.024)$. As the breast cancer type with the worst prognosis, TNBC is characterized by a lack of ER, PR and HER2 expression. Due to a lack of known specific therapeutic targets, patients with TNBC do not benefit from conventional endocrine-targeted therapy, anti-HER 2 drugs or other types of chemotherapy, resulting in high mortality $(25,26)$. The highly-specific MCT-4 expression in TNBC may become a potential novel target for prediction and treatment. Unlike most other studies, the present study thoroughly investigated the association between MCT-4 expression and AR, which is the most widely expressed steroid receptor protein in normal breast tissues and is detectable in $\sim 90 \%$ of primary breast cancers and $75 \%$ of metastatic lesions. It has been reported that high AR expression is linked to adverse reactions to endocrine therapy (27). In the present study, MCT-4 expression was significantly associated with AR status and may provide a novel perspective for the treatment of breast cancer.

In previous years, the clinical and prognostic value of MCT-4 has been identified in colorectal cancer $(12,19)$, oral squamous cell carcinoma (13), prostate cancer (13) and lung adenocarcinoma (28). Although experimental evidence suggests that MCT-4 may be a potential target for cancer therapy (29), the function of this membrane protein in breast cancer remains unclear. In liver cancer, Luo et al (30) demonstrated that hypoxia-inducible factor $1-\alpha$-mediated MCT-4 expression enhanced glycolysis in liver cancer cells, resulting in the release of products, such as lactic acid, into 
Table II. Association between MCT-4 expression and clinicopathological characteristics of patients with breast cancer ( $\mathrm{n}=145$ ).

\begin{tabular}{|c|c|c|c|c|}
\hline \multirow[b]{2}{*}{ Features } & \multirow[b]{2}{*}{ Total no. } & \multicolumn{2}{|c|}{ MCT-4 expression } & \multirow[b]{2}{*}{ P-value } \\
\hline & & Low, n (\%) & High, n (\%) & \\
\hline Age, years & 145 & & & 0.719 \\
\hline$\leq 60$ & & $48(57.8)$ & $35(42.2)$ & \\
\hline$>60$ & & $34(54.8)$ & $28(45.2)$ & \\
\hline pT stage & 145 & & & 0.018 \\
\hline $\mathrm{pT} 1 / \mathrm{pT} 2$ & & $76(60.3)$ & $50(39.7)$ & \\
\hline $\mathrm{pT} 3 / \mathrm{pT} 4$ & & $6(31.6)$ & $13(68.4)$ & \\
\hline $\mathrm{N}$ stage & 145 & & & 0.471 \\
\hline No & & $44(59.5)$ & $30(40.5)$ & \\
\hline N1/N2/N3 & & $38(53.5)$ & $33(46.5)$ & \\
\hline Histologic grade & 145 & & & 0.030 \\
\hline G1 & & $3(75)$ & $1(25)$ & \\
\hline $\mathrm{G} 2$ & & $73(60.3)$ & $48(39.7)$ & \\
\hline G3 & & $6(30)$ & $14(70)$ & \\
\hline Clinical stage & 145 & & & 0.507 \\
\hline I & & $14(60.92)$ & $9(39.1)$ & \\
\hline II & & $49(59.0)$ & $34(41.0)$ & \\
\hline III & & $19(48.7)$ & $20(51.3)$ & \\
\hline Oestrogen receptor & 137 & & & 0.001 \\
\hline Negative & & $22(38.6)$ & $35(61.4)$ & \\
\hline Positive & & $57(71.3)$ & $23(28.7)$ & \\
\hline Progesterone receptor & 137 & & & 0.004 \\
\hline Negative & & $42(47.7)$ & $46(52.3)$ & \\
\hline Positive & & $36(73.5)$ & $13(26.5)$ & \\
\hline Human epidermal growth factor receptor 2 & 138 & & & 0.980 \\
\hline Negative & & $57(58.8)$ & $40(41.2)$ & \\
\hline Positive & & $24(58.5)$ & $17(41.5)$ & \\
\hline Ki67 & 136 & & & 0.043 \\
\hline Low & & $55(64.7)$ & $30(35.3)$ & \\
\hline High & & $24(47.1)$ & $27(52.9)$ & \\
\hline Androgen receptor & 139 & & & 0.033 \\
\hline Negative & & $19(44.2)$ & $24(55.8)$ & \\
\hline Positive & & $61(63.5)$ & $35(36.5)$ & \\
\hline
\end{tabular}

MCT-4, monocarboxylate transporter 4.

the extracellular environment. The acidic microenvironment promotes the production of pro-inflammatory cytokines, contributing to arsenite-induced liver cancer (30). Compared with the normal breast tissues in the present study, the positive rate of MCT- 4 expression in breast cancer samples was significantly increased, indicating that there may be different metabolic mechanisms between normal breast and breast cancer cells. Additionally, high MCT-4 expression was significantly associated with short OS, acting as an independent predictor of poor prognosis in patients with breast cancer, which is consistent with the findings of Curry et al (31) in head and neck squamous cell carcinoma. In addition, high MCT4 expression in the stroma is associated with the progression of gastric cancer and predicts a poor prognosis (32). At present, the understanding of the molecular basis of MCT-4 mainly focuses on its role in transporting lactic acid from tumour cells to the extracellular matrix $(5,33)$, which increases the acidity of the extracellular environment and maintains an acidic tumour microenvironment (5). This shift results in the activation of a number of cytokines by matrix metalloproteases or other proteases to facilitate tumour neovascularization, cell survival and epithelial-mesenchymal transition to aid cancer cell survival (33).

In conclusion, MCT-4 expression was significantly higher in breast cancer tissues compared with adjacent normal tissues. Furthermore, MCT-4 high expression was demonstrated to be associated with pT status, ER status, PR status, Ki67 and AR status, and was closely associated with 
Table III. Cox proportional hazard model of the overall survival rate of patients with breast cancer.

\begin{tabular}{|c|c|c|c|c|}
\hline \multirow[b]{2}{*}{ Factor } & \multicolumn{2}{|c|}{ Univariate analysis } & \multicolumn{2}{|c|}{ Multivariate analysis } \\
\hline & P-value & $\mathrm{HR}(95 \% \mathrm{CI})$ & P-value & HR $(95 \%$ CI $)$ \\
\hline Age ( $\leq 60$ vs. $>60$ years $)$ & 0.983 & $1.007(0.549-1.846)$ & 0.447 & $0.743(0.345-1.599)$ \\
\hline $\mathrm{T}(\leq 4$ vs. $>4 \mathrm{~cm})$ & 0.079 & $0.547(0.279-1.073)$ & 0.806 & $0.907(0.416-1.979)$ \\
\hline HER2 (negative vs. positive) & 0.591 & $0.835(0.432-1.613)$ & 0.877 & $0.933(0.390-2.236)$ \\
\hline ER (negative vs. positive) & 0.115 & $1.627(0.888-2.979)$ & 0.788 & $0.886(0.365-2.147)$ \\
\hline PR (negative vs. positive) & 0.204 & $1.544(0.790-3.018)$ & 0.897 & $0.937(0.351-2.502)$ \\
\hline Ki67 (negative vs. positive) & 0.386 & $0.759(0.407-1.416)$ & 0.747 & $0.892(0.446-1.784)$ \\
\hline AR (negative vs. positive) & 0.430 & $1.295(0.682-2.460)$ & 0.553 & $1.271(0.575-2.814)$ \\
\hline Lymph node metastasis (N0 vs. N1/2/3) & 0.036 & $0.513(0.275-0.958)$ & 0.027 & $0.419(0.194-0.904)$ \\
\hline MCT-4 expression (low vs. high) & 0.001 & $0.092(0.039-0.217)$ & 0.001 & $0.096(0.039-0.240)$ \\
\hline
\end{tabular}

MCT-4, monocarboxylate transporter 4; HR, hazard ratio; ER, oestrogen receptor; PR, progesterone receptor; HER2, human epidermal growth factor receptor 2 ; AR, androgen receptor.

A

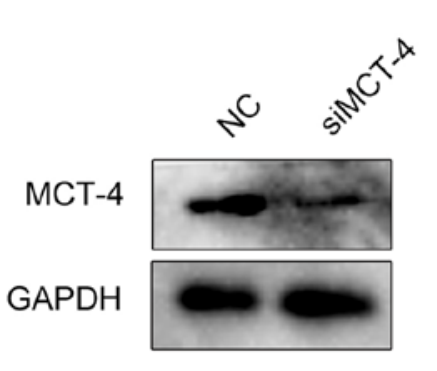

C

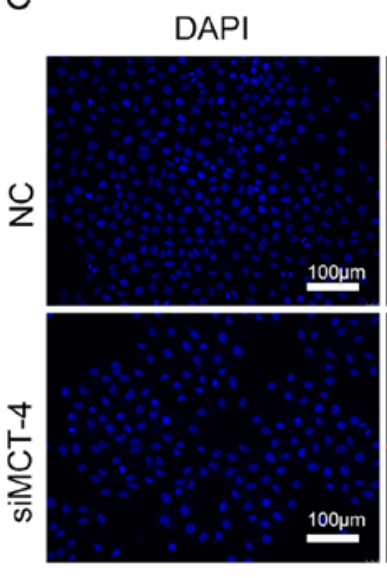

B

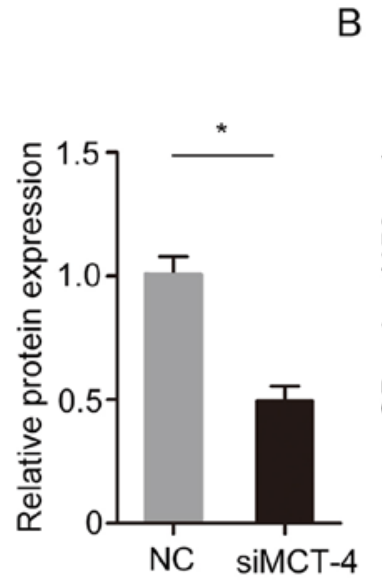

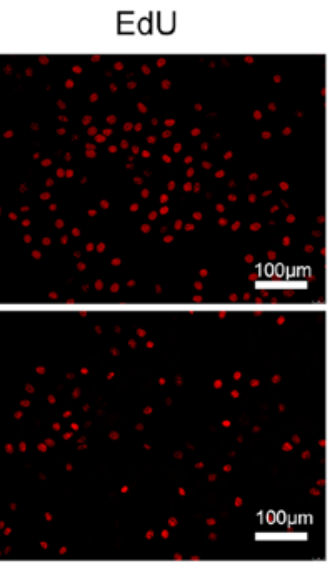
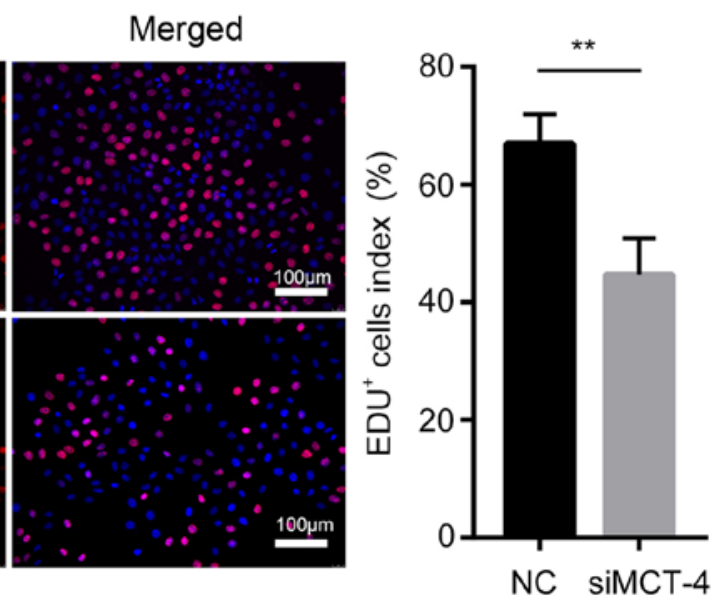

Figure 5. MCT-4 promotes cell viability in vitro. (A) siRNA-mediated MCT-4 knockdown efficiency detection in MCF-7 cells. (B) MCT-4 knockdown significantly decreased MCF-7 cell viability. (C) MCT-4 knockdown significantly inhibited MCF-7 cell proliferation. ${ }^{*} \mathrm{P}<0.05 ;{ }^{* * *} \mathrm{P}<0.01 ;{ }^{* * *} \mathrm{P}<0.001$. MCT-4, monocarboxylate transporter 4; si, small interfering; NC, negative control; EdU, 5-ethynyl-2'-deoxyuridine.

pathological grade. Silencing MCT-4 decreased cell viability of breast cancer cells (MCF-7). Taken together, these results suggest that MCT- 4 may be used as a novel potential predictor and treatment target for patients with breast cancer. 


\section{Acknowledgements}

Not applicable.

\section{Funding}

The present study was supported by the Key Research Projects on Application Foundation of Sichuan Science and Technology Department (grant no. 2017JY0030).

\section{Availability of data and materials}

All data generated or analyzed during this study are included in this published article.

\section{Authors' contributions}

SX, YS and MX designed and conducted the experiments, and wrote the manuscript. HZ, ZW and HW provided the research materials and analyzed the data. All authors agree to be accountable for all aspects of the research. All authors read and approved the final manuscript.

\section{Ethics approval and consent to participate}

The present study was conducted in accordance with the Declaration of Helsinki and approved by the Ethics Review Committee of the Yibin First People's Hospital (Yibin, China; approval no. Y2018010601) and the Ethics Review Committee of Southwest Medical University (Luzhou, China; approval no. Z2018-178-01). Written informed consent was obtained from all patients for the use of their tissues in the present study.

\section{Patient consent for publication}

Not applicable.

\section{Competing interests}

The authors declare that they have no competing interests.

\section{References}

1. Xi J, Feng J, Li Q, Li X and Zeng S: The long non-coding RNA lncFOXO1 suppresses growth of human breast cancer cells through association with BAP1. Int J Oncol 50: 1663-1670, 2017

2. Lu J, Tan M and Cai Q: The Warburg effect in tumor progression: Mitochondrial oxidative metabolism as an anti-metastasis mechanism. Cancer Lett 356: 156-164, 2015.

3. Gatenby RA and Gillies RJ: Why do cancers have high aerobic glycolysis? Nat Rev Cancer 4: 891-899, 2004.

4. Fang JS, Gillies RD and Gatenby RA: Adaptation to hypoxia and acidosis in carcinogenesis and tumor progression. Semin Cancer Biol 18: 330-337, 2008.

5. Pinheiro C, Longatto-Filho A, Azevedo-Silva J, Casal M, Schmitt FC and Baltazar F: Role of monocarboxylate transporters in human cancers: State of the art. J Bioenerg Biomembr 44: 127-139, 2012

6. Halestrap AP: The monocarboxylate transporter family-Structure and functional characterization. IUBMB Life 64: 1-9, 2012.

7. Bonen A, Miskovic D, Tonouchi M, Lemieux K, Wilson MC, Marette A and Halestrap AP: Abundance and subcellular distribution of MCT1 and MCT4 in heart and fast-twitch skeletal muscles. Am J Physiol Endocrinol Metab 278: E1067-E1077, 2000.
8. Philp NJ, Yoon H and Lombardi L: Mouse MCT3 gene is expressed preferentially in retinal pigment and choroid plexus epithelia. Am J Physiol Cell Physiol 280: C1319-C1326, 2001.

9. Doyen J, Trastour C, Ettore F, Peyrottes I, Toussant N, Gal J, Ilc K, Roux D, Parks SK, Ferrero JM and Pouysségur J: Expression of the hypoxia-inducible monocarboxylate transporter MCT4 is increased in triple negative breast cancer and correlates independently with clinical outcome. Biochem Biophys Res Commun 451: 54-61, 2014.

10. Fisel P, Kruck S, Winter S, Bedke J, Hennenlotter J, Nies AT, Scharpf M, Fend F, Stenzl A, Schwab M and Schaeffeler E: DNA methylation of the SLC16A3 promoter regulates expression of the human lactate transporter MCT4 in renal cancer with consequences for clinical outcome. Clin Cancer Res 19: 5170-5181, 2013.

11. Fisel P, Schaeffeler E and Schwab M: Clinical and functional relevance of the monocarboxylate transporter family in disease pathophysiology and drug therapy. Clin Transl Sci 11: 352-364, 2018.

12. Gotanda Y, Akagi Y, Kawahara A, Kinugasa T, Yoshida T, Ryu Y, Shiratsuchi I, Kage M and Shirouzu K: Expression of monocarboxylate transporter (MCT)-4 in colorectal cancer and its role: MCT4 contributes to the growth of colorectal cancer with vascular endothelial growth factor. Anticancer Res 33: 2941-2947, 2013.

13. Hao J, Chen H, Madigan MC, Cozzi PJ, Beretov J, Xiao W Delprado WJ, Russell PJ and Li Y: Co-expression of CD147 (EMMPRIN), CD44v3-10, MDR1 and monocarboxylate transporters is associated with prostate cancer drug resistance and progression. Br J Cancer 103: 1008-1018, 2010.

14. Hemdan T, Malmstrom PU, Jahnson S and Segersten U: Emmprin expression predicts response and survival following cisplatin containing chemotherapy for bladder cancer: A validation study. J Urol 194: 1575-1581, 2015.

15. Kim Y, Choi JW, Lee JH and Kim YS: Expression of lactate $/ \mathrm{H}^{+}$ symporters MCT1 and MCT4 and their chaperone CD147 predicts tumor progression in clear cell renal cell carcinoma: Immunohistochemical and The Cancer Genome Atlas data analyses. Hum Pathol 46: 104-112, 2015.

16. Pinheiro C, Sousa B, Albergaria A, Paredes J, Dufloth R, Vieira D, Schmitt F and Baltazar F: GLUT1 and CAIX expression profiles in breast cancer correlate with adverse prognostic factors and MCT1 overexpression. Histol Histopathol 26: 1279-1286, 2011.

17. Szubert S, Szpurek D, Moszynski R, Nowicki M, Frankowski A, Sajdak S and Michalak S: Extracellular matrix metalloproteinase inducer (EMMPRIN) expression correlates positively with active angiogenesis and negatively with basic fibroblast growth factor expression in epithelial ovarian cancer. J Cancer Res Clin Oncol 140: 361-369, 2014.

18. Zheng D, Zhu X, Ding X, Zhu X, Yin Y and Li G: Sensitive detection of CD147/EMMPRIN and its expression on cancer cells with electrochemical technique. Talanta 105: 187-191, 2013.

19. Zhu S, Chu D, Zhang Y, Wang X, Gong L, Han X, Yao L, Lan M, Li Y and Zhang W: EMMPRIN/CD147 expression is associated with disease-free survival of patients with colorectal cancer. Med Oncol 30: 369, 2013.

20. McClelland GB and Brooks GA: Changes in MCT 1, MCT 4, and $\mathrm{LDH}$ expression are tissue specific in rats after long-term hypobaric hypoxia. J Appl Physiol (1985) 92: 1573-1584, 2002.

21. Lokuhetty D, White VA, Watanabe R, Cree IA, et al: WHO Classification of Tumours, 5th Edition, Volume 2: Breast Tumours. Lyon, France, IARC Press, 2019.

22. Livak KJ and Schmittgen TD: Analysis of relative gene expression data using real-time quantitative PCR and the 2(-Delta Delta C(T)) Method. Methods 25: 402-408, 2001.

23. Maria RM, Altei WF, Selistre-de-Araujo HS and Colnago LA: Impact of chemotherapy on metabolic reprogramming: Characterization of the metabolic profile of breast cancer MDA-MB-231 cells using ${ }^{1} \mathrm{H}$ HR-MAS NMR spectroscopy. J Pharm Biomed Anal 146: 324-328, 2017.

24. Long Y, Gao Z, Hu X, Xiang F, Wu Z, Zhang J, Han X, Yin L, Qin J, Lan L, et al: Downregulation of MCT4 for lactate exchange promotes the cytotoxicity of NK cells in breast carcinoma. Cancer Med 7: 4690-4700, 2018.

25. Perou CM, Sorlie T, Eisen MB, van de Rijn M, Jeffrey SS, Rees CA, Pollack JR, Ross DT, Johnsen H, Akslen LA, et al: Molecular portraits of human breast tumours. Nature 406: 747-752, 2000.

26. Kreike B, van Kouwenhove M, Horlings H, Weigelt B, Peterse H, Bartelink $\mathrm{H}$ and van de Vijver MJ: Gene expression profiling and histopathological characterization of triple-negative/basal-like breast carcinomas. Breast Cancer Res 9: R65, 2007. 
27. Bleach $\mathrm{R}$ and McIlroy $\mathrm{M}$ : The divergent function of androgen receptor in breast cancer; analysis of steroid mediators and tumor intracrinology. Front Endocrinol (Lausanne) 9: 594, 2018

28. Ruan Y, Zeng F, Cheng Z, Zhao X, Fu P and Chen H: High expression of monocarboxylate transporter 4 predicts poor prognosis in patients with lung adenocarcinoma. Oncol Lett 14: 5727-5734, 2017.

29. Mathupala SP, Parajuli P and Sloan AE: Silencing of monocarboxylate transporters via small interfering ribonucleic acid inhibits glycolysis and induces cell death in malignant glioma: An in vitro study. Neurosurgery 55: 1410-1419, 2004.

30. Luo F, Zou Z, Liu X, Ling M, Wang Q, Wang Q, Lu L, Shi L, Liu Y, Liu Q and Zhang A: Enhanced glycolysis, regulated by HIF-1 $\alpha$ via MCT-4, promotes inflammation in arsenite-induced carcinogenesis. Carcinogenesis 38: 615-626, 2017.

31. Curry J, Tassone P, Gill K, Tuluc M, BarAd V, Mollaee M, Whitaker-Menezes D, Rodeck U, Luginbuhl A, Cognetti D, et al: Tumor metabolism in the microenvironment of nodal metastasis in oral squamous cell carcinoma. Otolaryngol Head Neck Surg 157: 798-807, 2017.
32. Yan P, Li YH, Tang ZJ, Shu X and Liu X: High monocarboxylate transporter 4 protein expression in stromal cells predicts adverse survival in gastric cancer. Asian Pac J Cancer Prev 15: 8923-8929, 2014

33. Sanita P, Capulli M, Teti A, Galatioto GP, Vicentini C, Chiarugi P, Bologna $\mathrm{M}$ and Angelucci A: Tumor-stroma metabolic relationship based on lactate shuttle can sustain prostate cancer progression. BMC cancer 14: 154, 2014 